\title{
Metodologia da problematização: respostas de lições extraídas da prática
}

\section{Problematization methodology: answers from lessons obtained through practice}

\author{
Neusi Aparecida Navas Berbel ${ }^{1}$
}

\begin{abstract}
Resumo
Este texto constitui uma reflexão teórico-prática elaborada a partir de questões que surgem da prática da Metodologia da Problematização, no contato com pessoas que a praticam ou desejam praticá-la quando conhecem a proposta. A primeira parte do texto traz um breve relato do percurso já realizado, acompanhado de algumas produções. Na segunda parte são apresentadas perguntas registradas de vivências com professores interessados na Metodologia. As respostas às perguntas, antes de serem afirmações definitivas, são sugestões possíveis extraídas da prática dessa Metodologia em diferentes situações, elaboradas como possíveis lições, após cerca de 20 anos de experiência, elaboração e reelaboração teórico-prática com e sobre a Metodologia da Problematização. O objetivo principal é possibilitar maior compreensão e segurança para aqueles que querem experimentar a Metodologia com o Arco de Maguerez em sua realidade de ensino, de pesquisa ou de orientação de estudos, ou ainda superar possíveis dificuldades que enfrentam nesse caminho. A bibliografia que acompanha o texto é mais uma contribuição ao leitor que deseja informar-se sobre os fundamentos e sobre algumas experiências já realizadas com essa orientação metodológica. Fica aqui o registro da necessidade de continuidade da reflexão sobre a metodologia, pois é significativo o caminho já percorrido em sua exploração.
\end{abstract}

Palavras-chaves: Metodologia da problematização. Questões frequentes. Lições da prática.

\begin{abstract}
This text consists in a theoretical-practical reflection elaborated from questions that emerge from the practicing of Problematization Methodology, in touch with people that practice or wish to practice it when get to know its proposal. The first part of the text brings a brief report about the already accomplished journey, accompanied by other productions. At the second part are presented some questions registered from experiences with teachers interested in the Methodology. The answers to the questions are not definitive affirmations, but possible suggestions extracted from the practice of this Methodology in different situations, elaborated as possible lessons, after about twenty years of experience, theoreticalpractical elaboration and reelaboration with and about the Problematization Methodology. The greatest objective is to make possible a bigger comprehension and assurance for those who either wants to try the Methodology with the Maguerez'Arch in their reality of teaching, researching or studies orientation, overcome possible difficulties that they face on this way. The bibliography that accompanies the text is one more contribution to the reader that wishes to get informed about the foundations and some experiences already realized with this methodological orientation. Keeps here the register of the reflection continuity needs about the Methodology, for it is meaningful the way already crossed on its exploration.
\end{abstract}

keywords: Problematization methodology. Frequent questions. Lessons from practice.

Doutora em Educação. Professora a posentada da Universidade Estadual de Londrina. E-mail: neusiberbel@gmail.com 
Temos buscado divulgar a Metodologia da Problematização em todas as oportunidades possíveis. Nossa crença em seu potencial pedagógico tem-nos estimulado a aceitar convites para palestras e mini-cursos e também a desenvolver vivências com grupos específicos de modo a torná-la conhecida e compreendida. Desafiamos os professores e alunos a experimentá-la, pelo menos uma vez, para constatar na prática o que leem ou o que ouvem sobre esta Metodologia.

Uma das situações que nos dão maior prazer, neste trabalho, é aquela em que podemos esclarecer alguma dúvida de pessoas realmente interessadas, que buscam aplicar a Metodologia em sua realidade e se deparam com obstáculos, teóricos ou práticos, ou com alguma insegurança que desejam superar. É com essa mesma finalidade que ora reapresentamos este texto, com alguns ajustes e atualizações.

\section{Sinais do Percurso já Realizado}

Os artigos que temos publicados têm trazido alguns elementos teóricos interessantes que podem dar um certo apoio ao professor ou ao estudante, quanto ao pano de fundo teórico-métodológico para o uso da Metodologia da Problematização.

Com base em Juan Díaz Bordenave e Adair Martins Pereira, com seu livro Estratégias de ensino aprendizagem, pudemos compreender que a inspiração de Maguerez para o seu Arco, que depois teria sido aperfeiçoado por Juan Díaz Bordenave, estaria nos princípios de uma Pedagogia Problematizadora que, por sua vez, se inspiraria numa concepção crítica da Educação, numa perspectiva transformadora da sociedade.

Escrevemos, então, o primeiro artigo (BERBEL, 1995) em que situamos a Metodologia da Problematização como uma alternativa adequada ao ensino superior. Fizemos uma busca de autores que já teriam alguma ideia sobre ela e pessoas e áreas que já estariam utilizando o Arco de Maguerez, com denominações diversas. Descrevemos a
Metodologia e o fizemos utilizando, neste artigo, o próprio caminho metodológico do Arco.

Já num segundo artigo (BERBEL, 1996), buscamos associá-la ao conceito de práxis, com o sentido atribuído por Sánchez Vázquez (1977), pois percebemos nitidamente, e por isso procuramos demonstrar, diversas relações entre o Arco do Maguerez e o conceito de práxis.

$\mathrm{Na}$ sequência, escrevemos um outro artigo mostrando como a Metodologia da Problematização tem relação com os ensinamentos de Paulo Freire. E demonstramos que existe entre eles uma relação mais que perfeita (BERBEL, 1999). Estes três artigos têm também orientado alunos e professores, que aí encontram algum suporte para justificar teoricamente a sua experiência com a Metodologia da Problematização.

Além disso, temos procurado estimular nossos alunos a escreverem seus trabalhos com esmero de modo que possam ser publicados. Isto resultou numa série de artigos que foram apresentados na revista Semina de 1995 e 1996 e em vários livros que depois publicamos (BERBEL, 2001b, por exemplo), além de outros artigos publicados em periódicos nacionais. Maura M. M. Vasconcellos colaborou conosco num destes livros, com o artigo sobre Fundamentos Pedagógicos e Filosóficos da Metodologia da Problematização (VASCONCELLOS, 1999).

Nesse percurso, há um aspecto interessante a salientar e que tem chamado a atenção de nossos interlocutores: se Paulo Freire propôs uma Pedagogia Problematizadora, por que vimos tratando esse caminho como uma Metodologia da Problematização? Por que denominamos esta proposta como Metodologia da Problematização? Temos respondido que, como professora de Dídática, sabemos da importância do caminho metodológico para possibilitar, na prática, a concretização das ideias, das propostas teóricas. Não temos a pretensão de nos colocar à altura das reflexões e ensinamentos do grande educador Paulo 
Freire, mas nele nos inspiramos em vários pontos para fortalecer a especial alternativa metodológica que podemos exercitar na prática. Por isso, desde o primeiro artigo de 1995, passamos a denominar esse caminho de Metodologia da Problematização, com o uso do Arco de Maguerez (apud BORDENAVE; PEREIRA, 1982).

Temos utilizado essa Metodologia com diferentes focos e, com isso, fomos descobrindo que, por identificar o problema na realidade e buscar a solução para ele, ela se presta, em primeiro lugar, para resolver problemas de trabalho, seja na educação seja em outros setores, mediante a indispensável associação entre a teoria e a prática. Descobrimos também que, para o desenvolvimento de trabalhos científicos, ela é uma excelente alternativa. Para alunos de iniciação científica na graduação, para alunos de especialização e suas monografias, para alunos da graduação em seus trabalhos de conclusão de curso (TCC) com o caráter de iniciação científica, para alunos que realizam os estágios em instituições escolares ou outras etc. Sempre buscamos, ao nos aproximarmos da realidade, aprender com ela e obter elementos para levar algo de volta a esta realidade, em forma de reflexões ou sugestões para responder ou solucionar os problemas focalizados, ou pelo menos amenizá-los.

Algumas dissertações de mestrado têm procurado demonstrar a validade da Metodologia da Problematização para a realização de estudos em unidades de ensino em diferentes áreas como exemplos, PRADO JUNIOR, 2001; TACLA, 2000. Participamos também da orientação de uma tese de Doutorado (GIANNASI, 1999), em que a Metodologia da Problematização foi utilizada num curso de Educação continuada e a distância, através da Internet, orientando profissionais a realizarem estudos em suas áreas específicas, visando o seu desenvolvimento crítico.

Além disso, todos os nossos alunos de Mestrado em Educação, a partir de 1994 e por muitos anos, experimentaram a Metodologia da Problematização em estudos que realizavam sobre sua realidade de ensino. Utilizamos também esta Metodologia como caminho de pesquisa, como por exemplo, num projeto integrado que coordenamos e no qual atuamos, sobre avaliação no ensino superior (BERBEL et al., 2001), que teve continuidade com um outro projeto, sobre outros aspectos do mesmo objeto de investigação (BERBEL, 2001a).

Portanto, este caminho tem-se revelado fantástico em termos de oportunidades de estudo de uma realidade, oportunidades de reflexão, de elaboração teórico-prática, de experimentos de diversas naturezas relacionados ao ensino e ao desenvolvimento do pensamento de nível superior, por professores e alunos de graduação e pósgraduação. Enfim, é uma alternativa metodológica que nos tem dado muitos motivos de alegria e realização.

O desafio de um aprofundamento teórico nos levou, em meados de 2009, a iniciar uma pesquisa buscando compreender a epistemologia que estaria na base do Arco de Maguerez. Acabamos por desvendar três versões de explicação para o Arco, em suas instâncias de aplicação - a do próprio Charlez Maguerez, depois a de Juán Díaz Bordenave e, por último, a de Berbel. Na continuidade, identificamos algumas pedagogias que teriam características semelhantes às da Metodologia da Problematização, quando aplicada ao ensino, e níveis de configuração epistemológica, quando utilizada como caminho de pesquisa. Tais elaborações estão registradas no texto intitulado "A metodologia da problematização com o arco de Maguerez. Uma reflexão teóricoepistemológica" (BERBEL, 2012a) e sintetizadas em artigos de Berbel e Sánchez Gamboa (2011) e de Berbel (2012b).

O potencial da Metodologia da Problematização com o Arco de Maguerez continua sendo explorado, especialmente no ensino com pesquisa na área da saúde, em diversos momentos de diversos cursos e níveis de ensino, estimulados, mais recentemente, pelas orientações em documentos formais da área, 
como na Política Nacional de Educação Permanente em Saúde (BRASIL, 2009) e por autores como Davini (2009), por exemplo.

\section{Questões Mais Frequentes Sobre a Prática da Metodologia da Problematização}

Durante aproximadamente duas décadas, vimos deparando com questões às vezes bastante complicadas para serem respondidas. Não temos todas as respostas e disso temos certeza, por isso nossa busca continua. Durante esse tempo, recebemos sempre algumas perguntas de ordem prática. Dessas, resolvemos registrar algumas e, pelo fato de já contarmos com uma pequena história de (re)construção teórico-prática sobre a Metodologia da Problematização, ensaiar possíveis respostas, contando para isso com a memória de nossa experiência. Acreditamos que, com um texto desta natureza, podemos contribuir para esclarecer interessados na Metodologia da Problematização, sobre questões de ordem prática, que nem sempre aparecem ou ficam suficientemente explícitas em textos com preocupações mais teóricas.

As questões que aqui trazemos são dificuldades que os professores desejam superar, registradas a partir de diferentes situações que vivenciamos com professores e alunos de graduação ou pós graduação, ao longo dos últimos 10 anos, das quais passamos a mencionar algumas, como uma espécie de reflexão teórico-prática compartilhada com nossos possíveis leitores. Vamos então às questões.

1 - Como estimular os alunos para estudar com a Metodologia da Problematização?

Uma preocupação que os professores nos têm apresentado é: Como preparar os alunos para trabalhar com esta Metodologia? Como motivar os alunos para esta alternativa? Em geral, nossos interlocutores justificam sua pergunta com base no fato de que o estudo com a Metodologia da Problematização demanda dos participantes mais trabalho que outras metodologias convencionais. Vamos refletir um pouco, recuperando alguns elementos para justificar uma resposta possível.

Apesar de todas as publicações existentes sobre tendências educacionais, enfoques metodológicos, alternativas de procedimentos de ensino existentes, a situação pedagógica e metodológica no ensino superior ainda hoje deixa muito a desejar, em termos tanto de inovações quanto da própria adequação aos objetivos que os professores costumam explicitar. Nós encontramos muitos cursos que ainda se mantêm numa perspectiva de ensino tradicional, utilizando-se de aulas predominantemente expositivas, e fazendo com que os alunos permaneçam na posição de ouvintes que anotam e repetem em provas ou exames. Não somos a única a observar isso. Quando abrimos livros que falam sobre ensino em diversas áreas, encontramos esta constatação, seja na Arquitetura, seja nas Licenciaturas, no Direito etc.

Por outro lado, responsáveis por alguns cursos, ao se mobilizarem para inovar seus currículos, e consequentemente sua metodologia, encontram resistência por parte de muitos professores que se perguntam: formados como fomos no ensino tradicional, chegamos até onde chegamos, a sermos os profissionais que somos, professores pertencentes a uma carreira etc. Isso significa que o método pelo qual fomos ensinados foi positivo. Por que mudar então? Já ouvimos isso em reuniões, em que pessoas se levantam para fazer esse tipo de argumentação. Disso decorre a dificuldade de mudança, que não é da área, mas de profissionais de determinadas áreas que procuram sustentar ou repetir aquele método com que foram ensinados duas ou três décadas atrás.

Podemos redarguir a essa manifestação, simplesmente perguntando: - Será que foi a metodologia de ensino ou o ensino nos moldes tradicionais os únicos fatores responsáveis pela chegada desse profissional à posição que hoje ocupa? Sabemos que não. 
Consequentemente, muitos alunos estão habituados a trabalhar no sistema tradicional, com uma forma pedagógica mais conservadora e até mesmo reprodutora dos conhecimentos elaborados por outros. As inovações, com a tecnologia, acabam acontecendo através de slides, de transparências coloridas e mais recentemente com o uso do data-show, mas continuam sendo mantidas as aulas expositivas, ilustradas com tais recursos. Os alunos, como se poderia esperar, habituados a receber informações e a decorá-las para reproduzir posteriormente, reagem a propostas metodológicas que tragam novidades, que solicitem deles uma nova forma de atuar ou um esforço maior. Temos percebido isso em diferentes áreas e diferentes locais. Muitos alunos pensam, ainda, que, se o professor não estiver o tempo todo "dando aula", "dando conteúdos" e explicando oralmente, não está atuando em seu papel. E eles cobram dos professores, que querem inovar, que retornem às aulas expositivas, que "dêem o máximo de conteúdo" porquanto eles vão precisar para exercer sua profissão. Esta é uma posição equivocada dos alunos, mas é consequência dos anos em que foram expostos a uma única forma de ensinar e aprender.

Uma metodologia que solicite deles um desempenho ou atuação diferente diante do conteúdo, diante da realidade, em que o papel do professor seja estimular, provocar, apoiar, nem sempre é bem percebida pelos alunos.

Às vezes, leva-se um semestre ou um ano inteiro para que os alunos se conscientizem de que foi possível aprender mais e fixar de forma mais efetiva as noções pelo caminho pelo qual foram conduzidos, do que se estivessem naquela mesma situação de repetição de conteúdos para as provas. No entanto, até chegar a esse ponto, o professor passa por alguns aborrecimentos, pois alguns alunos até se indispõem contra ele.

Então, como preparar o aluno para estudar com a Metodologia da Problematização, de forma a não encontrar esses obstáculos todos ou a superá-los?
Podemos dizer que absolutamente não há uma receita, mas vamos levantar algumas hipóteses que talvez possam ser testadas.

Por exemplo, o professor deve ter clareza da proposta que quer experimentar com seus alunos. Precisa conhecê-la e ter argumentos sobre sua validade. Hoje já temos várias experiências que podem servir como exemplos. Então, o primeiro ponto é o professor ter clareza sobre o que significa esta proposta. Trata-se, sem dúvida, de nova proposta, mesmo que não o seja em termos de existência, mas é nova para o professor que vai experimentá-la pela primeira vez e para os alunos que também não a conhecem. Essa é uma condição imprescindível, mas como o professor se prepara para encará-la? A resposta pode ser: lendo, fazendo cursos, planejando, discutindo com colegas, buscando orientação de pessoas que já tenham uma experiência maior, enfim, preparandose de diversas formas para então propor o trabalho aos seus alunos.

Um segundo ponto que consideramos importantíssimo é o seguinte: consciente das características da Metodologia, o professor deverá destacar, no momento de apresentar a proposta, os ganhos, aprendizagens e desenvolvimento que os alunos estarão experienciando. Como argumentos, podemos lembrar: a relação entre teoria e prática está presente, a busca da informação em diversas fontes, para confrontá-las, está presente; isto para resolver um problema extraído da realidade, e é isso que dá muito mais objetividade ao estudante, em qualquer atividade que vá realizar, que numa situação apenas teórica, abstrata, hipotética. Não dizemos que também não seja válida esta situação. É válida, mas a Metodologia da Problematização tem a característica de partir da realidade concreta onde a temática e o estudo possam ter elementos vivos para fornecer ao estudante. Se o professor, ao conhecer as características da Metodologia, destacar que tipos de desempenhos intelectuais, sociais, éticos etc., os alunos estarão exercitando por esse caminho, ele poderá mostrá-los e 
conquistar uma maior adesão dos alunos, que necessitam compreender a importância disso para a vida profissional hoje, para a vida de cidadãos hoje.

Estamos atravessando um momento histórico de dificuldades mundiais com relação ao emprego, ao trabalho, ao destaque de profissionais. Dos profissionais estão sendo solicitadas, hoje, habilidades de pensamento, de decisão, de atuação diferenciada. Uma pessoa que tem um desempenho simples e inicial não consegue um trabalho que requeira um nível maior de habilidades, e que, consequentemente, pode proporcionar-lhe um salário melhor. $\mathrm{O}$ professor pode mobilizar $\mathrm{o}$ aluno para mostrar que vantagens ele teria como Ser em formação, como estudante, como futuro profissional e como pessoa que tem um potencial incrível que pode estar adormecido enquanto ele fica exercitando apenas a sua memória. Em síntese, o professor pode e deve mostrar aos alunos o que é que eles vão exercitar, como vantagens para a sua aprendizagem e para o seu desenvolvimento, em diferentes sentidos.

Outro ponto importante: o professor precisa estabelecer uma relação de companheirismo nesse trabalho: ele não vai dar respostas, ele vai provocar os alunos a buscá-las. Ele vai estimular, incentivar, vai também apoiá-los. É preciso que o professor se prepare para estar constantemente acompanhando o desenvolvimento dos alunos. E esta promessa feita logo no primeiro dia, quando ele apresenta sua proposta de trabalho, é fundamental: o aluno precisa saber que vai poder contar com o professor em diferentes momentos. Essa é mais uma possibilidade de conquistar, de envolver, de estimular o aluno.

Como quarta pista, podemos afirmar que as orientações dadas aos alunos para a realização de cada etapa devem ser suficientemente claras, exemplificadas, ilustradas. O professor precisa tornar a atividade viável, factível. Ele precisa convencer o aluno de que é capaz, levando-o a construir o conhecimento gradativamente, conforme as etapas o vão solicitando. O aluno deve sentir-se mais uma vez orientado, apoiado e acompanhado.

Um outro aspecto a considerar é que esta é uma Metodologia que, para além do desenvolvimento do participante/estudante, visa uma transformação da realidade em algum grau. Não vamos resolver os problemas do mundo ou da realidade na qual estamos inseridos, mas vamos exercitar intervenções, mesmo que pequenas, em alguma parcela da realidade. Uma proposta dessa natureza, que envolva uma ação reflexiva, analítica, dialética, exige do professor uma postura nesta direção. O professor não pode atuar de modo tradicional ou com valores, crenças, posturas tradicionais e ser bem-sucedido na realização de uma atividade pedagógica transformadora. Deverá questionar-se: Eu quero realmente experimentar este caminho? Eu acredito que eu posso fazer isso? Eu acredito que esta Metodologia prepara o meu aluno para uma postura transformadora? Se estiver convencido que sim, está pronto para experimentá-la.

No entanto é preciso contar com o apoio institucional, pois o professor deverá tirar o aluno da sala de aula tradicional (quatro paredes, carteira, mesa, quadro de giz etc.) para a realização do estudo, e o apoio institucional é importante. O professor deve obtê-lo com antecedência, antes de apresentar a proposta aos alunos.

Exemplos de trabalhos já realizados podem ser mostrados; depoimentos de pessoas que já experimentaram podem ser trazidos aos alunos ou ao grupo que vai estudar um problema com a Metodologia da Problematização. Se quisermos ainda ampliar estas pistas, isto é, de como envolver os alunos, podemos programar com eles um esquema de publicação ou de apresentação de trabalhos em eventos de iniciação científica ou outros encontros. Se o aluno sabe que seu trabalho será valorizado pelo professor e que o professor vai acompanhá-lo até chegar ao ponto 
de ser apresentado como trabalho científico em algum evento relacionado à sua área, ele terá aí mais um motivo para dedicar-se com firmeza, com empenho, e obter bons resultados.

Acreditamos ter reunido algumas pistas para o professor, como um bom começo de caminho. São pistas possíveis, extraídas da prática vivenciada. Outras podem ser construídas.

2- Todos os temas podem ser estudados através da Metodologia da Problematização?

Em outras palavras, podemos usar a Metodologia da Problematização para estudar todos os temas em todas as áreas temáticas? Essa é uma questão muito interessante. Pelas características da Metodologia de levar os participantes a extraírem o problema de uma parcela da realidade e estudá-lo ao ponto de preparar-se, através de todos os conhecimentos adquiridos e elaborados, principalmente durante a teorização, para atuar sobre ela, podemos dizer que alguns conteúdos se prestam mais para isso do que outros.

Temos sugerido aos professores que elejam dentre todos os temas que têm destacado para trabalhar com seus alunos, aqueles que são mais polêmicos, que dão margem à maior elaboração pelos alunos. Ou aqueles que podem ser analisados de diferentes ângulos, por exemplo, do ponto de vista histórico, legal, ético, técnico, econômico, político, ideológico. Não que todos os temas tenham que ser tratados sob todas essas dimensões, mas há temas que são passíveis de serem trabalhados de diferentes ângulos, em diferentes dimensões. E também há aqueles conteúdos que nós podemos/devemos estudar através de outras formas metodológicas. Costumamos brincar ou perguntar às pessoas se ensinaríamos o uso da crase, que é um acento gramatical, com a Metodologia da Problematização. E, em geral, chegamos à conclusão que não. Para fixar uma regra gramatical, devemos compreender em que situações a utilizamos, devemos exercitar seu uso para melhor compreendê-la e melhor fixar esta utilização, mas o que é que crase tem de econômico, político, social, ético etc.? Teríamos que nos esforçar um pouco (?) para chegarmos a tais respostas.

A sugestão é elegermos aqueles temas que são de/permitem maior elaboração pelos alunos. Questões cujas respostas estejam certas ou erradas são questões de informação, na maioria das vezes, e as respostas podem ser obtidas facilmente nos livros. No entanto, questões que dão margem a pensamentos divergentes, por conta de posturas diferentes, de histórias de vida diferentes, estas sim são mais adequadas para serem trabalhadas com o uso da Metodologia da Problematização. Se vamos trabalhar duas ou três temáticas ou apenas uma durante o semestre com essa Metodologia, devemos eleger aquela(s) que mais se $\operatorname{presta}(\mathrm{m})$ para levar o aluno a exercitar o processo, etapa por etapa, de modo que chegue a elaborar o conhecimento por meio da reflexão sobre os dados da investigação.

Há temáticas mais condizentes que outras. E nós temos uma imensa gama de alternativas metodológicas à nossa disposição. Algumas aprendizagens requerem a repetição até que se chegue ao domínio do movimento, da habilidade, do comportamento em si. Estas nem sempre são questionadas do ponto de vista econômico, social, ético, etc., e devem ser aprendidas pelo exercício. Como, por exemplo, na enfermagem, a preparação de uma bandeja para a assepsia, aplicar uma injeção, a medida da pressão etc.. Ou seja, certas habilidades precisam ser treinadas para serem bem realizadas. Em síntese, o professor deverá eleger, para ensinar com a Metodologia da Problematização, um tema baseado, essencialmente, na crença de que os alunos o possam desenvolver e de que ele pode ser analisado de diferentes ângulos. 
3- Com que tipos de participantes é mais adequado usar a Metodologia da Problematização?

Quem são os participantes quando se trabalha ou estuda utilizando-se a Metodologia da Problematização? Todo tipo de aluno ou pessoa pode aprender com esta metodologia? Esta é uma questão que vem sendo colocada constantemente por professores: Eu posso aplicar com alunos de qualquer nível de escolaridade?

Vamos tomar algumas características da Metodologia e ver o que ela solicita dos participantes. Em primeiro lugar, deverão olhar para a realidade, com um olhar crítico, analítico, para verificar aquilo que precisa ser modificado, transformado. Diante das várias possibilidades de observação, deverão eleger um problema considerado prioritário. Para isso os participantes precisam tomar uma decisão a partir do critério prioridade - esse pode ser um dos critérios. Ou o que é mais urgente estudar para atuar sobre a realidade, ou ainda sobre que situação nós temos mais condições de atuar. Estas são tomadas de decisão, que necessitam uma elaboração intelectual, cujo portador de um nível de pensamento concreto ainda não está preparado para realizar.

Temos sugerido para as pessoas que se utilizem da Metodologia da Problematização com o Arco de Maguerez a partir do $5^{\circ}$ ou $6^{\circ}$ ano do Ensino Fundamental. A partir daí teremos maiores chances de sucesso. É preciso perceber quando o aluno já é capaz de realizar abstrações, de elaborar o seu pensamento de forma crítica e de tomar decisões. Caso tenha essa capacidade, ele está em condição de trabalhar com a Metodologia.

Retomando as características da Metodologia, depois de termos elegido o problema e de o termos elaborado de forma a orientar todo o restante do processo, sobre ele vamos refletir: Por que será que esse problema existe? Por que será que este fenômeno se constitui um problema nessa parcela da realidade observada? Ou seja, que fatores podem estar influindo para a existência desse problema? E, ainda, uma segunda questão: Que determinantes maiores ou contextuais poderiam estar atuando para a existência desta situação? Vejam que mais uma vez nós precisamos de um pensamento analítico, crítico, sobre a realidade, e alunos da Educação Infantil e dos Anos Iniciais, em geral, ainda não estão preparados para realizar este tipo de operação mental.

Definir o que precisa ser estudado é mais um momento de tomada de decisão que exige a busca daquilo que é básico, que é essencial sobre o problema. Outra vez precisamos de critérios para a tomada de decisão. Além disso, a teorização vai indicar uma investigação propriamente dita, através de entrevistas, de questionário, de observação etc.. As informações coletadas deverão ser tratadas e analisadas para se chegar a algumas conclusões. Novamente as habilidades de análise e síntese são requeridas dos participantes. E assim vamos até o final, sempre mobilizando níveis de pensamento mais complexos.

Pensando assim, podemos utilizar a Metodologia da Problematização a partir da pré-adolescência em diante. Não se pode especificar exatamente uma idade cronológica, mas as séries escolares, a partir $5^{\circ}$ ou $6^{\circ}$, já são susceptíveis de um bom trabalho. Pelo menos já temos experiência nesse sentido. Um trabalho que acompanhamos que atesta nossa afirmação é a Dissertação de Mestrado de Matheus Fabrício Verona, defendida em 2009, em que trabalhou com educação ambiental com alunos de $5^{\circ}$ e $6^{\circ}$ ano (VERONA, 2009). Não vamos ter a expectativa de que o trabalho de alunos de $5^{\circ}$ ou $6^{\circ}$ série tenha o mesmo nível de elaboração que teria o de adultos ou de pessoas que cursam o $3^{\circ}$ grau ou ainda a pós-graduação.

O nível de expectativa em relação aos participantes deverá corresponder à sua condição de elaboração, ao nível de pensamento que já é capaz de manifestar. Estimulados, responderão, mas não podemos pretender que respondam adequadamente se eles ainda não possuem minimamente um desenvolvimento intelectual considerado apropriado para aquele momento e para aquele trabalho. 
Se levamos em conta o nível de pensamento requerido, acreditamos que qualquer tipo de participantes pode usufruir das vantagens da Metodologia da Problematização, sejam estudantes, professores, outros profissionais ou pessoas da comunidade, desde que entendam que o caminho proposto pelo Arco pode atender a seus objetivos.

4- Como fica a questão do tempo em relação à Metodologia da Problematização?

Essa é uma outra pergunta muito frequente. Refere-se ao tempo requerido para o estudo com a Metodologia da Problematização e isto é muito interessante porque o professor que se entusiasme e se decida a trabalhar com seus alunos utilizando a Metodologia da Problematização deverá saber, de antemão, que necessitará de mais tempo do que se optasse por trabalhar o tema através de uma aula expositiva, um estudo dirigido ou uma leitura seguida de resumo ou exercícios pelos alunos. A elaboração reflexiva e a elaboração coletiva requerem mais tempo. Passar por todas as etapas da Metodologia exige mais tempo do que se gasta com a maioria das outras modalidades de ensino.

Levar o aluno a atuar adequadamente naquilo que se lhe solicita em cada etapa exige realmente mais tempo. Por isso, nós voltamos àquela observação de que nem todas as temáticas precisam ser desenvolvidas com a Metodologia da Problematização. Se nos dispusermos a iniciar o Arco e completá-lo, provavelmente não chegaremos à metade do caminho percorrido, se comparado com o tempo gasto com o ensino convencional.

O que fazer, então? Se o professor ainda está atuando na escola com disciplinas, ele tem um conteúdo mínimo a ser trabalhado com seus alunos. E, em geral, para "dar conta" dos conteúdos curriculares, ele utiliza seu tempo com muitas aulas expositivas. Essa é uma das grandes preocupações dos professores: Como trabalhar todo o conteúdo se resolver optar por uma metodologia inovadora como a que focalizamos?

Logicamente, se pretendemos "dar todo o conteúdo", é melhor esquecer a Metodologia da Problematização. Mas, se for possível eleger um ou dois temas para trabalhar com a Metodologia da Problematização, os outros temas podem ser tratados por professores e alunos com outras formas de ensino/aprendizagem.

5- Como aplicar a Metodologia da Problematização em pequenos e grandes grupos?

Uma questão que muitas pessoas nos têm proposto é como aplicar a Metodologia da Problematização com grandes grupos. Sobre o tamanho dos grupos, quanto menor mais facilidade de interação entre as pessoas, de definição rápida das etapas e de possibilidade de supervisão contínua dos grupos ou das pessoas que estão participando. No entanto, se temos um grande grupo, por exemplo, uma sala de aula com 60 alunos, e mesmo assim queremos trabalhar com a Metodologia da Problematização para desenvolver alguma unidade, podemos nesse caso apresentar a sugestão, baseada em experiência que tivemos, de dividir a turma em grupos menores e cada pequeno grupo responsabilizar-se por observar a realidade por um ângulo e desenvolver passo a passo o estudo. Mas para isso é preciso contar com uma supervisão. Aí é que começa a dificuldade. $\mathrm{O}$ problema não está no fato de o grupo ser grande; o grande grupo pode trabalhar tranquilamente com a Metodologia da Problematização. A dificuldade maior é a do professor que tem que dar apoio a cada um dos pequenos grupos. Caso a classe tenha que ser dividida em oito grupos, o professor terá de desdobrar-se para atender as necessidades dos 8 grupos.

Isso não é fácil, principalmente se o professor dispuser de poucas horas para a disciplina. O que sugerimos é que o professor solicite, previamente, 
apoio institucional para poder contar com mais um colega para trabalhar esta disciplina com sua turma. Além de mais um colega, o professor também poderá solicitar à instituição mais algumas horas para o trabalho.

Isso que estamos dizendo também tem base na experiência por já termos participado de um projeto especial de ensino na área da saúde. Não se tratou de uma disciplina propriamente dita, mas de um projeto e, para cada pequeno grupo, houve um ou mais professores acompanhando. A dificuldade, repetimos, não está em trabalhar com o grande grupo, mas está na disponibilidade do professor para dar apoio aos vários grupos, considerando que há momentos em que os participantes necessitarão de trocar ideias, obter feedback, sentir-se seguros de estar caminhando nas etapas adequadamente. A supervisão dos trabalhos dos alunos é imprescindível e este é um ponto com o qual o professor necessita preocuparse com antecedência.

Já atuamos em uma turma com 42 alunos. Eram 7 grupos e cada grupo dedicou-se a estudar a temática avaliação da aprendizagem, sob um aspecto, a partir da observação da realidade, focalizando cada grupo uma escola. Além das horas que tínhamos com os alunos em sala de aula, que foi dividida para o desenvolvimento destas atividades e o desenvolvimento das outras unidades do programa, tínhamos a atuação junto a eles em horários extras, fora da sala de aula. Também atuamos com estagiários, num grupo com cinquenta e um alunos. Nesse caso, cinco professores dedicaram-se a acompanhar alguns grupos de dois ou três alunos cada. Então, realmente trabalhar com grande grupo requer condições diferentes das que temos normalmente para conduzir as disciplinas com outras metodologias.

Como já mencionamos antes, se estamos com um pequeno grupo, 10 ou 12 pessoas, tanto podemos ter um único problema eleito como prioritário pelo grupo e trabalhá-lo coletivamente o tempo todo, quanto trabalhá-lo com os 12 divididos em grupos pequenos. Então temos 2 ou 3 grupos analisando o mesmo problema, de forma independente um do outro, com o apoio do professor. Logicamente haverá pontos em comum, como uma literatura comum e alguns aspectos serão necessariamente estudados pelos grupos. Uma riqueza de aspectos poderá ser observada no momento da apresentação dos estudos, podendo-se perceber como cada grupo, composto por pessoas diferentes, pode conduzir diferentemente as reflexões e os estudos, fazer opções por procedimentos de coleta de informações diferentes, dar diferentes tratamentos às informações etc.

Então, essa riqueza, apesar de os alunos estarem trabalhando com o mesmo problema, vai mostrar diferentes ângulos abordados e diferentes possibilidades de reflexão e elaboração do mesmo problema por grupos diferentes.

Ainda pode acontecer que cada um dos participantes esteja buscando atuar individualmente, não obstante participe de momentos coletivos de reflexão. Com grupos pequenos, o professor pode atuar mais assiduamente acompanhando os participantes em suas reflexões, com o tempo para isso garantido institucionalmente.

Uma alternativa que podemos sugerir é que o tempo da disciplina seja dividido para que, ao longo do semestre ou do ano, o professor possa ter momentos de contato com os alunos para apoiálos na realização deste estudo e outros momentos em que os outros temas estarão sendo estudados/ discutidos. Ainda uma outra alternativa é a da elaboração de um projeto, cujo tema não seja necessariamente da disciplina. Para realizar este tipo de trabalho, o professor pode contar com a participação de alunos voluntários. Talvez nem todos possam participar de um trabalho extraclasse, extra-disciplina, mas aqueles que tiverem a disponibilidade poderão usufruir e muito da contribuição desta experiência. 
6 - É possível limitar o trabalho com a Metodologia da Problematização para certas áreas temáticas?

Esta é uma outra questão que nos propõem muitos professores. A resposta, de certo modo, já foi delineada, quando mencionamos a possibilidade de eleger uma unidade ou um tema da disciplina para trabalhar com a Metodologia da Problematização, enquanto outros temas são trabalhados de outras formas. Sem dúvida, é adequado fazer isso. Principalmente quando o professor a estiver pondo em prática pela primeira vez. Ele pode eleger um tema que considere o mais rico para ser explorado com esta Metodologia e que, dessa forma, poderá trazer maiores contribuições para a aprendizagem e para o desenvolvimento dos alunos. Então, é possível limitar o trabalho desenvolvido em áreas temáticas ou conteúdos com certeza. Isso pode ficar a cargo do professor ou ele pode decidir com os alunos. Quando estiver discutindo seu plano de trabalho, poderá tomar esta decisão com os alunos e, em conjunto, priorizar um dos temas para desenvolvê-lo com a Metodologia da Problematização.

\section{7- Como formular um problema?}

Esta é uma questão muito interessante. Por que é muito interessante? Porque a observação da realidade e a elaboração de um problema relevante de estudo é a mais difícil de todas as etapas. A formulação do problema tem sido, ao longo destes anos todos, o ponto mais delicado do trabalho com a Metodologia da Problematização. E por que isso? É possível levantar algumas hipóteses, antes de se chegar a uma resposta.

Uma delas seria porque não fomos acostumados, através de escolaridade apropriada, a problematizar, a formular problemas. Desde o início da nossa escolaridade, quando começamos a aprender a Matemática, as Ciências Biológicas, as Ciências Naturais etc., nos acostumamos a responder aos problemas formulados e trazidos pelos professores. Então, formular problemas não faz parte da nossa tradição de estudantes. É possível que saibamos reclamar muito das situações; enxergamos com facilidade os defeitos, aquilo que nos incomoda e até reclamamos, verbalizamos. Mas formular um problema de estudo se constitui um nível de elaboração que requer uma atenção especial, e então nos perguntamos: O que é um problema e o que é um problema de estudo? Temos várias possibilidades para chegar a uma resposta. No entanto, uma certeza já temos: quando formulamos um problema - ou formulamos uma questão que pensamos constituir-se um problema - e vamos buscar nos livros que tratam daquela temática que nos possibilitou levantar a questão e encontramos resposta, na verdade a questão formulada não constitui um problema. Então, um problema é uma questão para a qual não se encontra resposta pronta. Se temos uma resposta pronta para o problema, temos um caso de informação, uma informação que já está dada e disponível na literatura, nos livros, nas revistas, nos artigos que descrevem pesquisas etc.. O problema, em geral, surge de algo que necessita ser superado, de uma dificuldade tal que para responder a ela será preciso reunir uma série de elementos, principalmente porque, através da Metodologia da Problematização, o problema não é algo abstrato, o problema é algo extraído da realidade observada. Então, dificilmente vamos encontrar uma resposta pronta para um problema que estamos encontrando neste momento, nesta realidade.

Problematizar a realidade é muito diferente de formular um problema no sentido abstrato. Problematizar a realidade vai demandar estudos de diferentes aspectos que, conjugados, permitirão elaborar as hipóteses de solução. Isso porque a realidade é complexa, multidimensional.

Formular um problema tem-se constituído uma das maiores dificuldades das pessoas que trabalham com a Metodologia da Problematização. Em geral, temos presenciado a formulação de 
títulos de conteúdos como se fosse a formulação de problemas: falta disso, dificuldade daquilo, a evasão escolar, a indisciplina etc. As pessoas focalizam 'a indisciplina' e pensam que o problema já está posto. Mas que tipo de indisciplina? De onde partiu a observação da indisciplina? Que realidade é essa que nos mostra essa temática? E qual é a necessidade que está colocada para ser superada sobre esse tema?

A problematização requer que o participante do estudo localize e descreva suficientemente a situação de modo que a formulação conduza realmente à busca de solução. É possível até que não encontremos a solução completa, mas encontraremos, sem dúvida nenhuma, elementos para abrir um caminho para a solução.

Demerval Saviani (1996, p. 14) nos dá uma explicação de problema muito interessante:

[...] uma questão em si, não caracteriza o problema [...]; mas uma questão cuja resposta se desconhece e se necessita conhecer, eis aí um problema. Algo que eu não sei não é um problema; mas quando eu ignoro uma coisa que eu preciso saber, eis-me então diante de um problema. Da mesma forma, um obstáculo que é necessário transpor, uma dificuldade que necessita ser superada, uma dúvida que não pode deixar de ser dissipada são situações que se nos configuram como verdadeiramente problemáticas.

Além disso poderíamos afirmar que problematizar a realidade implica uma situação de envolvimento com a realidade desde o início e isso vai dar um caráter de concretude especial à situação observada, para a qual se deseja contribuir. Em geral, os problemas extraídos da realidade são tão ricos e desafiadores que vão levar a estudos de diferentes naturezas que possibilitem elaborar algumas hipóteses de solução.

Nossas afirmações estão centradas na convicção de que, na realidade social, cultural, educacional, nós não temos problemas que tenham uma única razão, uma única causa ou uma única manifestação. Na maioria das vezes, os problemas relacionados à saúde, à educação, à cultura são problemas complexos. O problema extraído da realidade é um problema que vai gerar um estudo sob diferentes ângulos, que influenciarão na definição dos pontos-chave, os quais constituem uma outra etapa que também pode ser melhor esclarecida.

Por mais simples que seja um problema, desde que extraído da realidade, e haja a intenção de que o estudante/participante se debruce sobre essa mesma realidade para estudá-la e sobre ela atuar, com algum grau de intervenção ou contribuição para a solução do problema, isso já sugere que a pergunta formulada constitui-se um problema. Retomando: se podemos encontrar uma resposta para esta questão na literatura existente, a questão formulada não se constitui problema, é questão de informação. No entanto, se para responder ao problema, temos que conjugar os dados da literatura - onde se encontram métodos, técnicas, teorias, alternativas, elaborações de experiências já existentes - com novos elementos extraídos desta mesma parcela da realidade - das pessoas ali envolvidas, dos fatos que estão acontecendo relacionados à questão central - então podemos quase garantir que estamos diante de um problema, cuja realidade soubemos problematizar.

Podemos formular o problema de diferentes formas: através de uma pergunta - se ela encerra o cerne da questão; através de afirmações (eu afirmo a existência de uma situação que eu considero problemática, que deve ser superada e que constitui uma dificuldade do desenvolvimento da vida naquela situação social); através de uma negação (não dispomos de condições suficientes para realizar um bom ensino no terceiro ano do ensino médio da escola tal - este pode ser um problema). Mais importante que o modo como se formula a questão é que o conteúdo esteja explícito nela. A dificuldade a ser superada deve estar explícita o suficiente na questão, porque o problema levantado por ela vai conduzir/orientar todas as outras etapas do estudo. 
8 - Como selecionar os pontos-chave do problema?

Para esta questão também podemos ensaiar algumas pistas. A primeira que podemos mencionar é a seguinte: se localizamos um problema da realidade e o descrevemos, a sua formulação já traz consigo alguns elementos delimitadores e nós vamos buscar, nas próprias palavras da questão, os pontos-chave. Se estou, por exemplo, com dificuldade de utilizar uma metodologia construtiva com um grupo de 60 ou 70 pessoas, eu já tenho alguns elementos importantes para destacar: o 10 é a questão da metodologia construtiva; o $2^{\circ}$, a questão do tamanho da turma, e por aí afora. $\mathrm{Na}$ própria formulação do problema podemos extrair os elementos que o estão constituindo.

Para tanto devemos analisar como está formulado o problema, extraindo daí as palavras que contenham significados cujo alcance podemos ampliar com o estudo. Dizendo de outro modo, a questão ou assertiva formulada traz palavras que poderão indicar os principais pontos a estudar. Às vezes não é tão simples, mas é do problema que vamos extrair os pontos-chave do estudo.

Uma outra possibilidade é fazer perguntas a respeito dessa formulação e buscar para os aspectos dela extraídos respostas em diferentes fontes. Por exemplo: um ponto-chave pode ser a localização do tema na literatura, outro pode indicar a localização daquele aspecto junto às pessoas que estão vivenciando o problema; um outro ponto ainda poderá registrar a própria percepção/experiência do participante a respeito daquele aspecto, entre outras possibilidades. Podemos destacar os pontos a estudar de diferentes ângulos, focalizando diferentes fontes possíveis de informações.

Ainda podemos formular os pontos-chave sobre dimensões diferentes daquele aspecto básico do problema. Por exemplo, se a questão disser respeito à avaliação, podemos procurar analisar a avaliação dos pontos de vista técnico, teórico, histórico, legal, empírico etc. Há, portanto, uma ampla possibilidade para cumprir essa etapa. O que precisamos é ter sensibilidade de perceber que aspectos são os mais importantes sobre o problema, de modo que, ao realizar tais estudos, possamos ter mais elementos para compreendê-lo e melhores condições para elaborar as soluções para ele, certos de que não vamos fazer estudos para continuar no plano abstrato a respeito da situação, já que quando o estudo se completar, o participante terá o compromisso de retornar à realidade com algum grau de intervenção.

Ainda podemos selecionar os ponto-chave pensando em diferentes pessoas que poderão informar sobre o problema. Se temos um problema de relação professor-aluno para ser resolvido, podemos ouvir do professor, o que ele tem a dizer a respeito da situação, podemos ouvir os alunos; podemos ouvir a coordenação da escola, a orientação pedagógica; podemos ouvir os pais a respeito da situação que está acontecendo. Reunindo informações destas fontes todas, compreendendo melhor o que está acontecendo, teremos mais segurança para elaborar as possíveis soluções. Existem várias possibilidades e todas elas são válidas, desde que haja a coerência entre os pontos-chave e o problema. E que os participantes tenham a clareza de que, ao estudar estes aspectos, estarão buscando melhores condições de lidar com o problema, de resolvê-lo ou então desencadear um processo de encaminhamento para a solução.

\section{Finalizamos o Texto Com a Certeza da Incompletude da Reflexão}

Quando iniciamos a experiência prática com a Metodologia da Problematização sabíamos de sua importância, mas nem de perto suspeitávamos de quão inesgotável era o seu potencial. A exploração feita tem revelado cada vez mais alternativas de aplicação e exigido maior aprofundamento teórico para que possamos melhor compreendê-la para estimular novas práticas. Das práticas, surgem as pistas para os estudos teóricos e de ambos, as convicções sobre o seu significado político-pedagógico. 
Este processo de reflexão teórico-prático aqui delineado não se esgota com as questões tratadas. Pelo contrário, estamos certos de que várias delas ficaram em suspenso, merecendo a continuidade do exercício de pensar por escrito e disponibilizar para as pessoas, pois são muitos e cada vez mais os interessados na Metodologia da Problematização.

\section{Referências}

BERBEL, N. A. N. A metodologia da problematização com o arco de Maguerez: uma reflexão teóricoepistemológica. Londrina: EDUEL, 2012a.

- A metodologia da problematização e os ensinamentos de Paulo Freire: uma relação mais que perfeita. In: BERBEL, N. A. N. (Org.). Metodologia da problematização: fundamentos e aplicações. Londrina: EDUEL, 1999.

- A metodologia da problematização em três versões no contexto da didática e da formação de professores. Revista Diálogo Educacional, Curitiba, v. 12, n. 35, p. 103-120. jan./abr. 2012 b.

. Metodologia da problematização no ensino superior e sua contribuição para o plano da práxis. Semina: Ciências Sociais e Humanas, Londrina, v.17, ed. esp., p. 7-17, out.1996.

- Metodologia da problematização: uma alternativa metodológica apropriada para o ensino superior. Semina: Ciências Sociais e Humanas, Londrina, v. 16, n. 2, ed. esp., p. 9-19, out. 1995.

- (Coord.). Avaliação da aprendizagem: uma investigação com experiências positivas em cursos de licenciaturas através da metodologia da problematização. Londrina: UEL, 2001a. Projeto de pesquisa.

. (Org.). Conhecer e intervir: o desafio da metodologia da problematização. Londrina, EDUEL, $2001 b$.

BERBEL, N. A. N. et al. (Coord.). Avaliação no ensino superior: significado e consequências. Londrina: UEL, 2001. Relatório final do projeto de pesquisa.
BERBEL, N. A. N.; SÁNCHES GAMBOA, S. A. A metodologia da problematização com o Arco de Maguerez: uma perspectiva teórica e epistemológica. Revista Filosofia e Educação, Campinas, v. 3, n. 2, p. 264-287, 2011.

BORDENAVE, J. D.; PEREIRA, A. M. Estratégias de ensino aprendizagem. 4.ed. Petrópolis: Vozes, 1982.

BRASIL. Ministério da Saúde. Política nacional de educação permanente em saúde. Brasília, 2009.

DAVINI, M. C. Enfoques, problemas e perspectivas na educação permanente dos recursos humanos de saúde. In: BRASIL. Ministério da Saúde. Política nacional de educação permanente em saúde. Brasília, 2009. p. 39-58.

GIANNASI, M. J. Oprofissional da informação diante dos desafios da sociedade atual: desenvolvimento de pensamento crítico em cursos de educação continuada e a distância via internet, através da metodologia da problematização. 1999. Tese (Doutorado em Ciência da Informação) - Fundação Universidade de Brasília, Brasília, 1999.

PRADO JÚNIOR, I. Desenvolvimento do pensamento crítico e criativo no ensino de arquitetura e urbanismo através da metodologia da problematização. 2001. Dissertação (Mestrado em Educação) - Universidade Estadual de Londrina, Londrina, 2001.

SÁNCHEZ VÁZQUEZ, Adolfo. Filosofia da práxis. 4. ed. Rio de Janeiro: Paz e Terra, 1977.

SAVIANI, D. Educação: do senso comum à consciência filosófica. 12. ed. São Paulo: Cortez, 1996.

TACLA, M. T. G. M. O potencial da metodologia da problematização no desenvolvimento do pensamento crítico em alunos de enfermagem. Dissertação (Mestrado em Educação) - Universidade Estadual de Londrina, Londrina, 2000.

VASCONCELLOS, M. M. M. Aspectos pedagógicos e filosóficos da metodologia da problematização. In: BERBEL, N. A. N. (Org.). Metodologia da problematização: fundamentos e aplicações. Londrina: EDUEL, 1999. 
VERONA, M. F. Aproximações entre o arco de Maguerez e as atividades de educação ambiental na escola: limites e possibilidades. 2009. Dissertação (Mestrado em Ensino de Ciências e Educação Matemática) - Universidade Estadual de Londrina, Londrina, 2009. 
